\title{
Analysis of hail damages and temperature series for peninsular Spain
}

\author{
A. Saa Requejo ${ }^{1}$, R. García Moreno ${ }^{2}$, M. C. Díaz Alvarez ${ }^{1}$, F. Burgaz ${ }^{3}$, and M. Tarquis ${ }^{1}$ \\ ${ }^{1}$ CEIGRAM. E.T.S.I. Agrónomos, Universidad Politécnica de Madrid, Spain \\ ${ }^{2}$ Universida de Da Coruña, Departamento de Ciencias Da Navegación e Da Terra, Facultad de Ciencias, Coruña, Spain \\ ${ }^{3}$ Entidad Nacional de Seguros Agrarios (ENESA) Ministry of the Natural, Rural and Marine Environments, Madrid, Spain
}

Received: 11 February 2011 - Revised: 12 June 2011 - Accepted: 19 October 2011 - Published: 22 December 2011

\begin{abstract}
Hail is a serious concern for agriculture on the Iberian Peninsula. Hailstorms affect crop yield and/or quality to a degree that depends on the crop species and the phenological time. In Europe, Spain is one of the countries that experience relatively high agricultural losses related to hailstorms. It is of high interest to study models that can support calculations of the probabilities of economic losses due to hail damage and of the tendency over time for such losses.

Some studies developed in France and the Netherdlands show that the summer mean temperature was highly correlated with a yearly hail severity index developed from hailrelated parameters obtained for insurance purposes. Meanwhile, other studies in the USA point out that a highly significant correlation between both is not possible to find due to high climatic variability.

The aim of this work is to test the correlation between average minimum temperatures and hail damage intensity over the Spanish Iberian Peninsula. With this purpose, correlation analyses on both variables were performed for the 47 Spanish provinces (as individuals and single set) and for all crops and four individual crops: grapes, wheat, barley and winter grains. Suitable crop insurance data are available from 1981 until 2007 and based on this period, temperature data were obtained.

This study does not confirm the results previously obtained for France and the Netherlands that relate observed hail damage to the average minimum temperature. The reason for this difference and the nature of the cases observed are discussed.
\end{abstract}

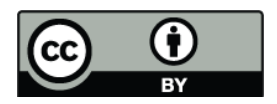

Correspondence to: A. Saa Requejo (antonio.saa@upm.es)

\section{Introduction}

Hail events represent an important natural disaster associated with great economic losses in several regions, mainly in $\mathrm{Eu}-$ rope. In Spain, the Combined Agrarian Insurance System covers hail events for most types of crop losses. Insurance coverage of hail events provides a means of economic recovery for most producers, mainly in the Mediterranean region, where the highest incidence of losses due to hailstorms is recorded (Llasat et al., 2009). In Spain, the indemnification for these losses reached 12.5 million euro in 2007.

Because of the nature of the hazards related to hail events, the State Agrarian Insurance Body (Entidad Nacional de Seguros Agrarios, ENESA), which coordinates and links administrative activities to guarantee the development of agrarian insurance in Spain, is interested in models that can support further calculations of the probabilities of economic losses and of the tendency for such losses to occur over time.

As mentioned by López et al. (2007), the correlation of the occurrence of hail events with climatic variables is a complicated problem because of the small area disturbed and because of the short time associated with hail events. Thus, although economic losses related to hail can be very important, the information on the climatology associated with hail events is very limited. It must also be recognised that most of the records of hailstorm events are made for insurance purposes.

Few studies address the climatology of hail events in Europe (Tuovinen et al., 2009; Webb et al., 2009; Hyvärinen and Saltikoff, 2010). Likewise, predictive models of hail events are lacking and are related in most of the cases with precipitation models. The problem is complicated because most investigations of this topic necessarily involve hailstorm time series that are non-homogeneous and non-continuous. For these reasons, model development for different geographical regions having different climatic

Published by Copernicus Publications on behalf of the European Geosciences Union. 
characteristics is very difficult (Piani, 2005; Fraile et al., 2003). Moreover, Piani et al. (2005) have observed that the relationship between hailstorm events and the parameters related to their occurrence seems unclear in published works on the subject.

The study of hailstorms is based on several meteorological parameters that are involved in conditions required to produce convection (temperature, instability, a deep humid layer in the low and middle troposphere and an updraft to initiate convection), as well as on the specific topographic characteristics of the geographical area studied (Dessens, 1995; Johns and Doswell III, 1995; Siemonov and Georgiev, 2003; López et al., 2007; García-Ortega et al., 2007). These studies based their descriptive and predictive models on several parameters that depended, in most of the cases studied, on the geographical area.

López et al. (2007) demonstrated that a reliable hailstorm study must include an adequate selection of meteorological variables that must depend on the specific geographical areas involved. Also, a model that proves valuable for a specific geographical area may not give satisfactory results for other areas (Lynn et al., 2004; Chagnon and Bigley, 2005). Indeed, López et al. (2007) obtained varying results when they attempted to apply models having high accuracy for Europe to other geographical areas. Some studies of hailstorm prediction have shown that instability indices by themselves are unable to produce successful predictions of the incidence of hailstorms (Manzato, 2003; Siedlecki, 2008). The predictions will depend strongly on the specific geographical area considered because the characteristics of this area will define the values and parameters associated with the particular meteorological conditions that occur (Kunz, 2007; Sánchez et al., 2009; Dimitrova et al., 2009)

Alesandrov and Hoogenboom (2001) demonstrated great variability in climatology at the local level for Georgia (USA). Uncertainties about parameters are not the only problem. Additional uncertainties arise because of climate change and associated phenomena (Soutworth et al., 2002; Reddy et al., 2002; Tao et al., 2004) and because of social perception of climatology in time (Liverman and Merideth, 2002; Camuffo and Sturaro, 2001).

The situation is even more complicated because most hailstorm studies are developed for insurance purposes, and only a few of these studies are published. For example, Dessens (1995) has found that an increase in night-time temperatures could have been related to an increase in the occurrence of severe storms in France over the period 19461992. This study shows that the summer mean temperature was highly correlated with a yearly hail severity index developed from hail-related parameters obtained for insurance purposes. Recently Berthet et al. (2011) found significant correlations between physical hail parameters recorded with hailpad network in France and some monthly temperatures.

Guided by this model, other authors found the same type of positive relationship between hail occurrence and minimum temperatures (Botzen et al. 2010). In fact, these authors found a strong positive correlation between hailstorm events and indicators of temperature and precipitation for the Netherlands. The combination of precipitation with maximum temperatures is noted by the authors as one of the best indicators of hailstorm events, whereas minimum temperature is the best indicator when temperature is used alone. The authors compared the results of this model with the results of other studies of the problem, e.g., a study of hailstorms occurring in Switzerland (Willemse, 1995). This author studied the statistical relationships of severe recorded hailstorm events, based on producer damage claims recorded since 1949, to other climate indicators. He concluded that the data could not be used to extrapolate future hailstorm trends because the data have too many uncertainties and because the period considered was too brief.

According to Changnon and Bigley (2005), the correlation of temperatures and hailstorm events is highly variable. Indeed, this correlation can have either negative or positive values. In countries where the spatial climatic variation is high (the USA, for example), the value obtained for the correlation may differ for different states. The same author studied the statistical relation between the mean temperatures across the USA and hail and thunderstorm frequencies on a daily basis (Changnon and Changnon, 2000, 2001). The results based on simple correlations for different states showed that the parameters were negative or positively correlated, depending on the state. In general, states in the High Plains had positively correlations and greater variability with time, meanwhile states near the Great Lakes exhibited negative correlations and less variability with time. In this sense, the relationship between the indicators seemed to depend on indicators related to geographical location.

McMaster (1999) evaluated the magnitude of hail damage to winter crops in Australia as the result of climate change in two geographical areas of New South Wales. The author used upper-air climatic data from a global climatic model to obtain forecasts of hail damage. For both geographical areas studied, the author found no change in hail-related crop damage losses in relation to the changes in climatic indicators that resulted from climatic change.

Mills (2005) mentioned that the losses due to damage caused by natural disasters have increased since 1960 . This increase has been produced in part by socioeconomic and demographic trends. These trends may be considered when forecasting extreme climate events, mainly for insurance purposes. Specifically, Mills et al. (2002) found a positively relation between lightning related insurance losses and average temperature in the USA.

Selected parameters that are valuable for predicting hail events in one specific site would not necessarily produce successful results in others as there are many factors influencing it. In the case of Spain, climatology and topography varies greatly among different geographical regions. Valleys, mountain ranges and plateaus generate a macroclimatic 


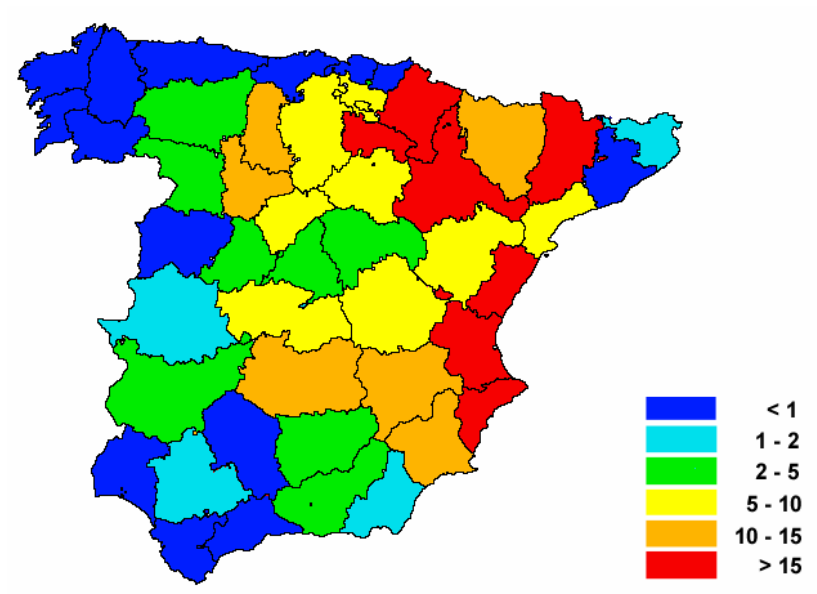

Fig. 1. Average hail claims per ha in 2005-2007 period for the provinces of Peninsular Spain.

diversity that can be perceived in Fig. 1 as hail claims variability for Peninsular Spain. Therefore, models of hailstorms must be defined on a case-by-case basis because orography and proximity to the sea may have only limited utility when predictive models are required for applications.

In this context, CEIGRAM researchers tried to apply a reliable model to relate hailstorm damage to summer temperature across the different regions of Spain. This research aimed, for insurance purposes, to contrast results that depended on specific parameters for each specific geographic space. For the analysis of this problem, the model developed by Dessens (1995) seemed appropriate for application to different Spanish regions. In this particular case, provinces were the regions considered. For this purpose, the relationship between average summer minimum temperature and hail severity index was studied for each growing season for different Spanish provinces. This trend was evaluated using separate, spatially-specific models. The aim of the study was to try to confirm the link found in France and the Netherlands between hail tendency and temperatures and to use the results of the investigation for insurance planning purposes. In addition, authors have evaluated the model applied by this study to assess the specific damages to particular crops. This evaluation sought to identify particular characteristics specific to different crops within a growing season.

\section{Data sets and methods}

This study covered Peninsular Spain. The subareas considered were the provinces shown in Fig. 1. The Spanish islands were not considered in this work. This selection has a political component because selection criteria are imposed by the availability of hail damage data, and such data are referenced to these areas. We consider 47 provinces of Peninsular Spain, each having an average extent of $10000 \mathrm{~km}^{2}$.

\subsection{Insurance data}

Hail insurance data from ENESA between 1981 and 2007 were considered to represent good estimates of hail damage intensity because crop insurance is widely implemented in Spain. Hail insurance covers the production of $79 \%$ of winter cereals, $78 \%$ of fruit crops, $39 \%$ of vineyard and $14 \%$ of olive trees, with a year average of 36901 hail claims in the period 2005-2007. The data are expressed in terms of a ratio between damage and production value, the loss-to-risk ratio for all crops insured against hail. Data were disaggregated by province. In Fig. 1 we can observe the great variation in hail claims per ha (or $10000 \mathrm{~m}^{2}$ ) due to climatology and crop insurance characteristics. However, data disaggregated by month could not be obtained. We thus obtained a separate series of 27 points (1981-2007) for each of 47 provinces as well as for the whole Peninsular Spain.

Five loss-to-risk ratio series were collected. The first series included all insured crops. Four similar series were collected for grapes, wheat, barley and winter grains (including wheat and barley). Series for other crops could not be considered, owing to historical changes in the standards for damage evaluation for insurance purposes by expert witnesses. These changes could generate non homogeneous data series.

\subsection{Climatologic data}

The climatologic data consisted of monthly average minimum temperatures recorded by the Agencia Estatal de Meteorología (AEMet, the Meteorological State Agency) and provided for this study through ENESA.

The weather stations were selected based on a grid approximately $40 \times 40 \mathrm{~km}$ in size. This selection was designed to ensure the availability of recent data, the fewest possible gaps in the data and the longest possible series. Several stations in each county were also selected to represent high- and lowaltitude areas. The locations of the 404 stations selected are shown in Fig. 2.

\subsection{Correlations}

Several data transformations are require to relate loss-torisk hail damage $(R)$ and summer minimum temperatures (Dessens, 1995). Because $R$ is highly variable, a logarithmic transformation was used to normalise data $(\log (1+R))$. Also, because the value of $R$ can be less than 1 or even zero, we added an increment of 1 to $R$ to avoid negative or indeterminate values. The transformed hail damage index used in our analyses was therefore calculated as the logarithm of $(1+R)$.

We constructed regional time series of summer minimum temperatures for each province by averaging the values for all the weather stations in the province. The average monthly minimum temperatures of June, July and August were used to compute average summer minimum 


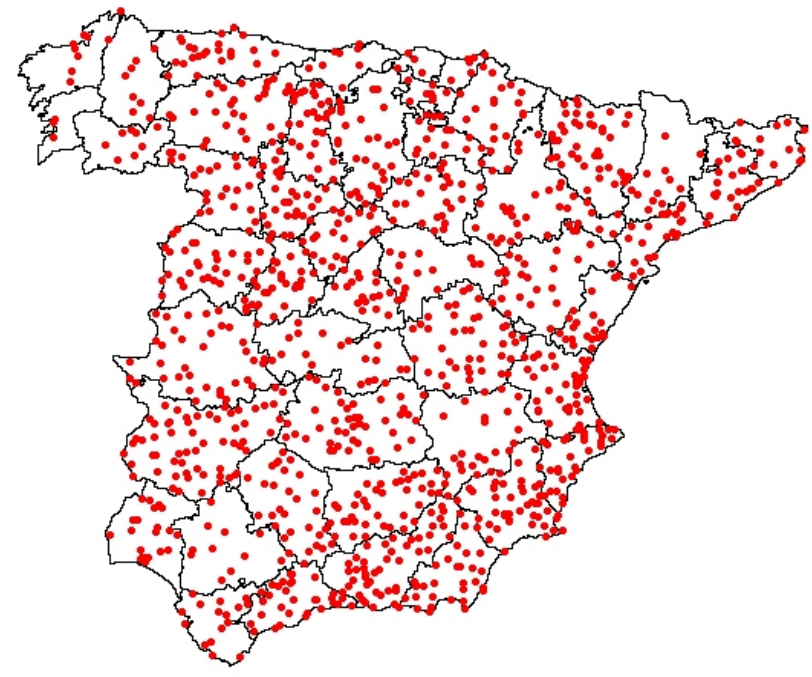

Fig. 2. Map of Spain with the 47 provinces considered. Points represent meteorological stations.

temperature, as proposed by Dessens (1995). We also compute, as this author, the parameters for Peninsular Spain as a single set.

Linear correlation obtained as a result of least squares fitting was used to relate year-to-year hail damage to summer minimum temperature. Also, a non-parametric Kendal's tau is computed.

\section{Results and discussion}

Correlations parameters for all 47 provinces and the whole Peninsular Spain with data for the agricultural seasons from 1981 to 2007 are presented in Table 1. Only two $5 \%$ significant Pearson correlation coefficients (see Fig. 3) are found. These significant correlations resulted for Huelva province (in the southwest) and Zamora province (in the central northwest). The proportion of total variance explained is $19 \%$. This value is slightly less than the value of $27 \%$ observed by Dessens (1995) and less than the value of $34 \%$ reported by Botzen et al. (2009), although these authors also found a variance of $18 \%$ in their model for within-greenhouse crops. However, the main difference between the results of our study and those obtained by these previous studies is that the previous authors cited found a positive relationship between hail damage and summer minimum temperatures. In contrast, our study found a similar positive relationship for Huelva and an inverse (negative) relationship for Zamora, whereas the remaining 45 areas showed no significant correlation. We also must remark that the provinces with significant relationships are categorised as low hail incidence provinces (see Fig. 1).
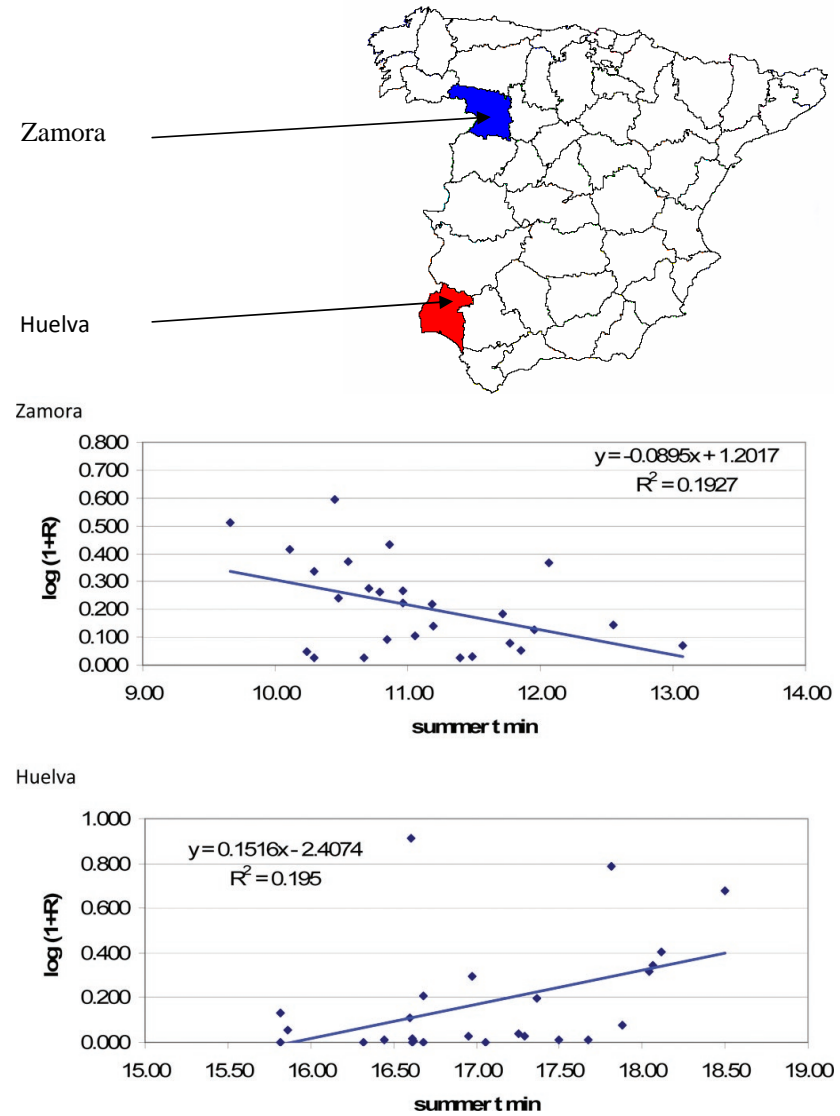

Fig. 3. Correlations estimated between hail damage and minimum summer temperature for Huelva and Zamora. Graphs show minimum summer temperature at the $\mathrm{x}$-axis (summer $t$ min) and transformed hail damage index $(\log (1+R))$ at the y-axis.

Considering Kendal's tau, the previous relations are confirmed (for Huelva and Zamora) and three new provinces presented $5 \%$ significant index (see Fig. 5). Málaga is a province with low frequency of hail claims and the data (Fig. 5) shows a high frequency of low damage ratio, with a descent slope very close to zero. Álava and La Rioja are two provinces with medium high and high hail claims per ha, that are below a classical hail damage area along with Navarra, a province with one of the highest hail claims located east of them. The hail claims tendency is to increase in both and it became significant at $5 \%$ according to Pearson's $r$ when the most extreme case is deleted. When the analysis is applied using Kendall's tau, that only considers arranging the cases. The estimation is less sensitive to this extreme case and therefore the tendency is significant without having to remove it.

As regards the whole Peninsular Spain, we also found no significant linear correlation with both methods (Fig. 4).

A comment about outliers is relevant here. We also computed correlation coefficients for all areas by deleting one, two or three years data, including all the possible variations. 
Table 1. Lineal correlations statistical parameters: Pearson $r$ and Kendall tau. Forty-seven provinces and the Peninsular Spain as a single set (PEN. SPAIN) are shown. (SoS $=$ Sum of squares; $n=$ number of data; $F=F$ test parameter; $p F=$ probability of $F ; r^{2}=$ correlation coefficient; K-tau $=$ kendall's tau parameter; $p \mathrm{~K}$-tau $=$ probability of $\mathrm{K}$-tau). $p F$ bold numbers correspond to $5 \%$ significant Pearson correlation coefficients. $p \mathrm{~K}$-tau bold numbers correspond to $5 \%$ significant index.

\begin{tabular}{|c|c|c|c|c|c|c|c|c|}
\hline AREA & SoS Regression & SoS Residual & $n$ & $F$ & $p F$ & $r^{2}$ & K-tau & $p \mathrm{~K}$-tau \\
\hline ALAVA & 0.726 & 0.647 & 27 & 3.045 & 0.093 & 0.109 & 0.271 & 0.024 \\
\hline ALBACETE & 0.675 & 0.637 & 27 & 1.485 & 0.234 & 0.056 & -0.140 & 0.153 \\
\hline ALICANTE & 1.612 & 1.455 & 27 & 2.683 & 0.114 & 0.097 & -0.180 & 0.095 \\
\hline ALMERIA & 0.674 & 0.629 & 25 & 1.802 & 0.192 & 0.067 & 0.100 & 0.242 \\
\hline ASTURIAS & 2.438 & 2.416 & 9 & 0.145 & 0.708 & 0.009 & 0.167 & 0.266 \\
\hline AVILA & 0.872 & 0.869 & 27 & 0.088 & 0.770 & 0.003 & -0.054 & 0.346 \\
\hline BADAJOZ & 1.236 & 1.148 & 27 & 1.910 & 0.179 & 0.071 & 0.128 & 0.174 \\
\hline BARCELONA & 0.802 & 0.702 & 27 & 3.576 & 0.070 & 0.125 & -0.214 & 0.059 \\
\hline BURGOS & 1.406 & 1.406 & 27 & 0.004 & 0.951 & 0.000 & 0.117 & 0.196 \\
\hline CACERES & 1.462 & 1.458 & 27 & 0.057 & 0.814 & 0.002 & -0.014 & 0.459 \\
\hline CADIZ & 0.006 & 0.006 & 11 & 0.297 & 0.591 & 0.012 & 0.346 & 0.070 \\
\hline CANTABRIA & 6.239 & 5.709 & 15 & 2.321 & 0.140 & 0.085 & 0.067 & 0.365 \\
\hline CASTELLON & 2.318 & 2.318 & 27 & 0.002 & 0.961 & 0.000 & -0.009 & 0.475 \\
\hline CIUDAD REAL & 1.351 & 1.351 & 27 & 0.005 & 0.946 & 0.000 & 0.003 & 0.492 \\
\hline CORDOBA & 0.079 & 0.079 & 27 & 0.107 & 0.746 & 0.004 & -0.100 & 0.233 \\
\hline CUENCA & 0.575 & 0.574 & 27 & 0.010 & 0.923 & 0.000 & -0.031 & 0.409 \\
\hline GERONA & 2.392 & 2.376 & 27 & 0.173 & 0.681 & 0.007 & -0.066 & 0.316 \\
\hline GRANADA & 0.868 & 0.866 & 27 & 0.066 & 0.800 & 0.003 & 0.100 & 0.233 \\
\hline GUADALAJARA & 0.784 & 0.769 & 27 & 0.488 & 0.491 & 0.019 & 0.106 & 0.220 \\
\hline GUIPUZCOA & 3.180 & 3.172 & 9 & 0.039 & 0.845 & 0.003 & 0.169 & 0.263 \\
\hline HUELVA & 1.700 & 1.368 & 23 & 6.057 & 0.021 & 0.195 & 0.328 & 0.014 \\
\hline HUESCA & 1.133 & 1.107 & 27 & 0.586 & 0.451 & 0.023 & 0.180 & 0.095 \\
\hline JAEN & 0.848 & 0.840 & 27 & 0.229 & 0.636 & 0.009 & -0.049 & 0.361 \\
\hline LA CORUÑA & 3.656 & 3.635 & 3 & 0.100 & 0.756 & 0.006 & 0.000 & 0.500 \\
\hline LA RIOJA & 1.666 & 1.492 & 27 & 2.914 & 0.100 & 0.104 & 0.237 & 0.042 \\
\hline LEON & 0.961 & 0.947 & 27 & 0.388 & 0.539 & 0.015 & -0.003 & 0.492 \\
\hline LERIDA & 2.703 & 2.423 & 27 & 2.883 & 0.102 & 0.103 & 0.214 & 0.059 \\
\hline LUGO & 4.523 & 4.300 & 19 & 1.297 & 0.266 & 0.049 & -0.099 & 0.276 \\
\hline MADRID & 1.055 & 1.040 & 27 & 0.364 & 0.552 & 0.014 & -0.003 & 0.492 \\
\hline MALAGA & 0.018 & 0.017 & 20 & 0.740 & 0.398 & 0.029 & -0.295 & 0.035 \\
\hline MURCIA & 1.118 & 1.094 & 27 & 0.557 & 0.463 & 0.022 & -0.117 & 0.196 \\
\hline NAVARRA & 1.018 & 0.953 & 27 & 1.695 & 0.205 & 0.063 & 0.168 & 0.109 \\
\hline ORENSE & 1.882 & 1.766 & 22 & 1.637 & 0.213 & 0.061 & 0.022 & 0.444 \\
\hline PALENCIA & 0.986 & 0.983 & 27 & 0.078 & 0.782 & 0.003 & 0.026 & 0.426 \\
\hline PONTEVEDRA & 1.260 & 1.220 & 17 & 0.787 & 0.384 & 0.032 & 0.250 & 0.081 \\
\hline SALAMANCA & 0.727 & 0.718 & 27 & 0.303 & 0.587 & 0.012 & 0.049 & 0.361 \\
\hline SEGOVIA & 0.971 & 0.971 & 27 & 0.004 & 0.949 & 0.000 & 0.100 & 0.232 \\
\hline SEVILLA & 0.405 & 0.380 & 27 & 1.691 & 0.205 & 0.063 & 0.145 & 0.144 \\
\hline SORIA & 1.060 & 1.058 & 27 & 0.047 & 0.830 & 0.002 & -0.060 & 0.331 \\
\hline TARRAGONA & 1.570 & 1.570 & 27 & 0.002 & 0.962 & 0.000 & 0.088 & 0.259 \\
\hline TERUEL & 0.738 & 0.736 & 27 & 0.067 & 0.798 & 0.003 & -0.031 & 0.409 \\
\hline TOLEDO & 1.021 & 1.006 & 27 & 0.371 & 0.548 & 0.015 & 0.049 & 0.361 \\
\hline VALENCIA & 1.661 & 1.566 & 27 & 1.519 & 0.229 & 0.057 & 0.191 & 0.081 \\
\hline VALLADOLID & 0.941 & 0.886 & 27 & 1.546 & 0.225 & 0.058 & -0.157 & 0.126 \\
\hline VIZCAYA & 4.732 & 4.419 & 13 & 1.489 & 0.236 & 0.066 & 0.181 & 0.195 \\
\hline ZAMORA & 0.670 & 0.541 & 27 & 5.967 & 0.022 & 0.193 & -0.283 & 0.019 \\
\hline ZARAGOZA & 1.091 & 1.080 & 27 & 0.247 & 0.623 & 0.010 & 0.128 & 0.174 \\
\hline PEN.SPAIN & 0.013 & 10.673 & 27 & 0.029 & 0.433 & 0.001 & -0.009 & 0.457 \\
\hline
\end{tabular}




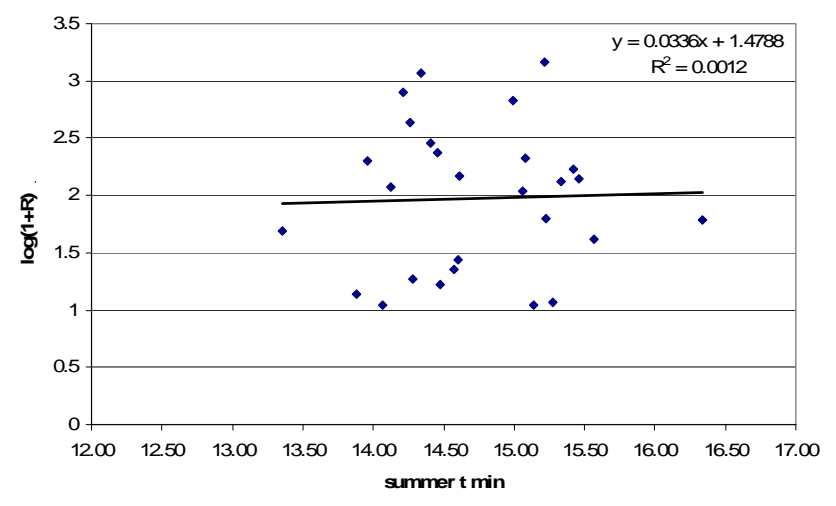

Fig. 4. Correlation estimated between hail damage and minimum summer temperature, at a $95 \%$ of significant level, for Peninsular Spain data as a single set and all crops. Graph shows minimum summer temperature at the $\mathrm{x}$-axis (summer $t$ min) and transformed hail damage index $(\log (1+R))$ at the $y$-axis.

Two provinces change to $5 \%$ significant coefficient deleting 1 point, four new provinces change to significant $r$ when 2 points are deleted, and 15 new provinces change when 3 points are deleted. Revising these changing provinces, we found cases where the set of points showed a spherical shape around the tendency and lost their thickness when some points located in the periphery were omitted. This causes an increase in the correlation coefficient; however, they do not seem to be specific outliers that should be eliminated as they are located in the context of the point set and characterize the variability in the time and space of hails.

Therefore, the relation between temperature and hail shows that it is relevant in hail claims for some provinces, but not for overall Peninsular Spain or for most of Spain.

We can explain these differences in terms of geographical and topographical characteristics. Compared with Holland and France, Spain has markedly higher variation in relief and is characterised by alternate plains, hilly and valley areas (see Cohen and Small, 1998, for the area distribution under and below $500 \mathrm{~m}$ ).

Another difference between our study and the works cited involves the length of the data series analysed. Dessens (1995) analysed data from the years 1946-1992. Botzen et al. (2009) analysed monthly data from the years 1990-2005. We could not use data for years before 1981 because ENESA and Agoseguro (a pool of private insurance companies) felt that homogeneity of the data could not be guaranteed prior to this date. This problem is also mentioned by Dessens (1995). The monthly data are only available for the past five years.

Another aspect of the heterogeneity of the data results from the characteristics of the contract periods and the insurance coverage. These characteristics produced annual time periods that could not be analysed effectively because they were too long. These considerations suggested that separate

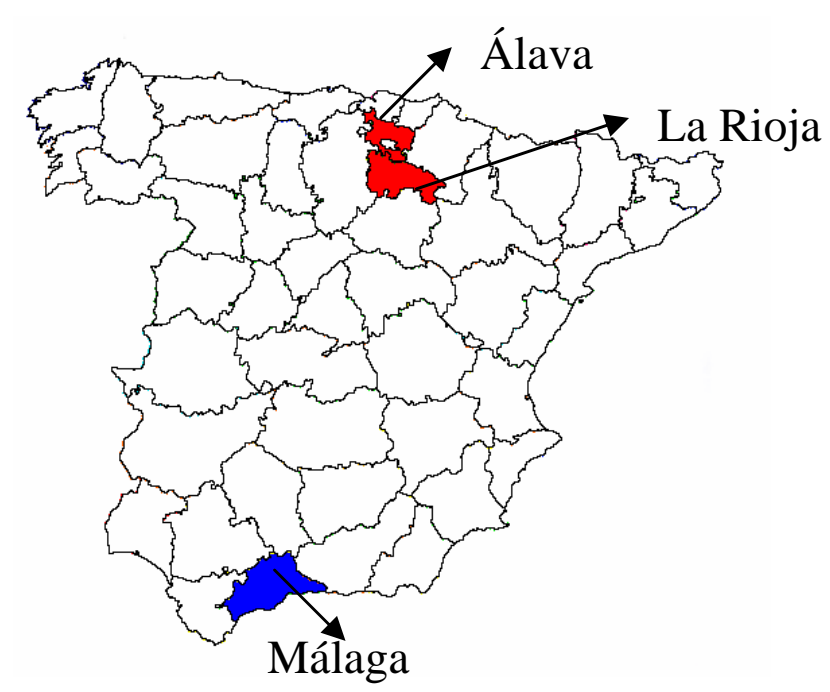

Álava

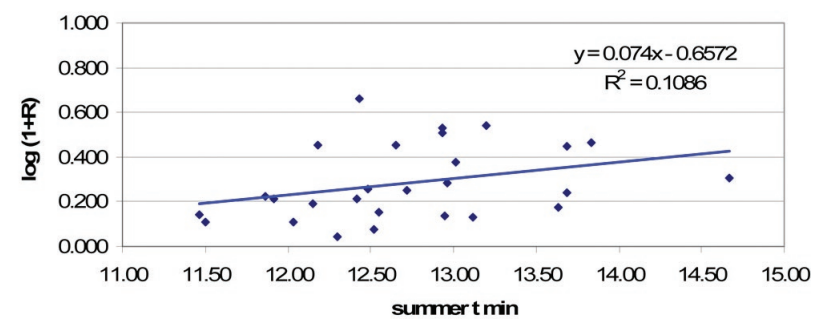

La Rioja
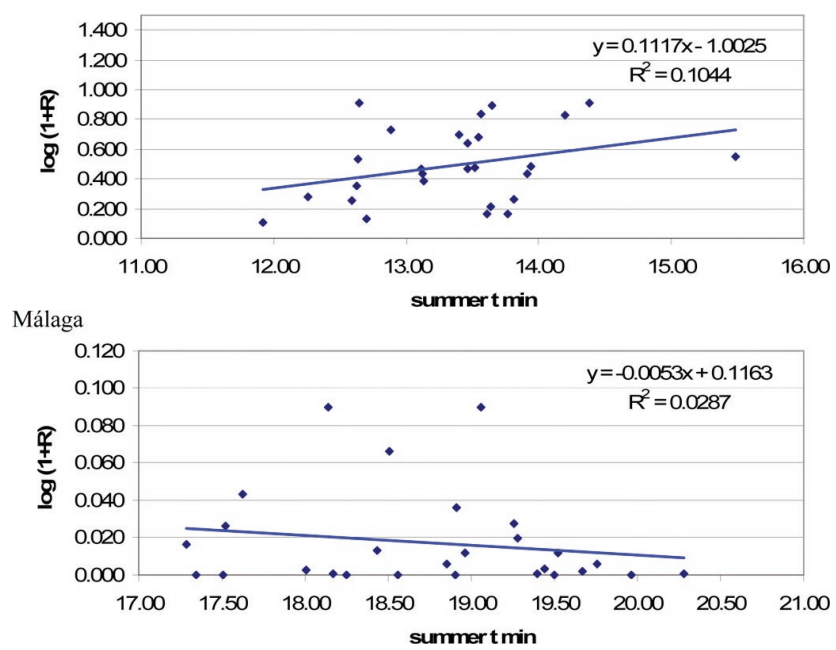

Fig. 5. Significant correlations according to Kendall's tau test between hail damage and minimum summer temperature, excluding those provinces that gave a Pearson $r$ significant. Graphs show minimum summer temperature at the $\mathrm{x}$-axis (summer $t \mathrm{~min}$ ) and transformed hail damage index $(\log (1+R))$ at the $y$-axis.

consideration of each crop could possibly improve the overall analysis of the relationship between hail damage and summer minimum temperatures. For this reason, several damage series were constructed for each crop, based on the importance 


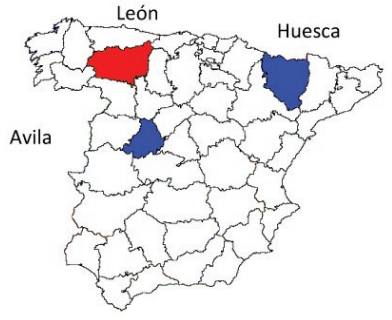

a)

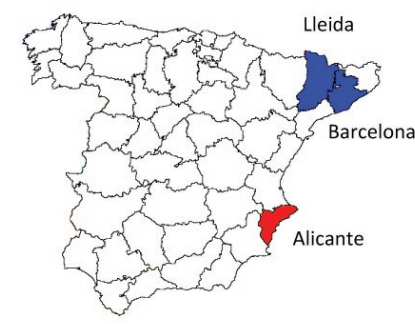

c)

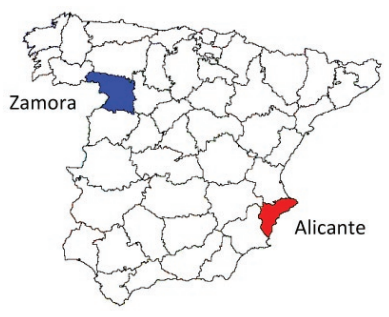

b)

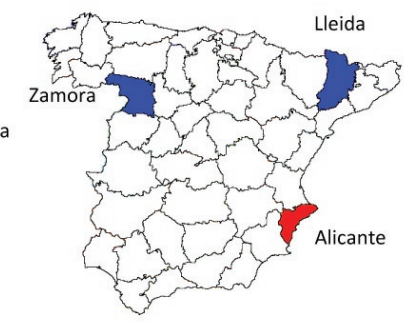

d)

Fig. 6. Positive (red) and negative (blue) significant correlations between hail damage and minimum summer temperature for (a) grapes, (b) wheat, (c) barley, and (d) all winter grains.

of the crop in Spanish agriculture. The crops considered were grapes, wheat, barley and all winter grains (including wheat and barley).

Tree fruit damage is of great relevance in the Spanish Peninsula. However, damage to these crops was not considered because the process used for insurance damage evaluation changed midway through the period of study.

Correlation analyses were performed for the 47 provinces and for the four crop types considered. The results of these analyses are shown in Fig. 3. Only two or three provinces exhibited $5 \%$ significant correlations between crop damage and temperature. These results are similar to those found for total agricultural damage. A negative 5\% significant correlation was found for grapes in Avila and Huesca and a positive correlation at León. A negative correlation was found for wheat at Zamora and a positive correlation at Alicante. A negative correlation was found for barley at Lérida and Barcelona and a positive correlation at Alicante. For all winter grains, a negative correlation was found at Zamora and Lérida and a positive correlation at Alicante.

The results for all the crops studied are consistent across Peninsular Spain. Only a few scattered areas exhibited statistically significant increasing or decreasing tendencies, with no clear connections evident in any case. Furthermore, only some provinces show consistent tendencies, and these tendencies occur in the context of crop inclusion, for example in the case of cereals in Alicante.

Our results are closer to the findings described by Changnon $(2000,2001,2005)$ for the USA than to the findings from France and The Netherlands. Although the area covered by our study is smaller than the area included in the study involving the USA, the lack of predictive consistency shown by the models evaluated should result from climatic variability (very strong in Peninsular Spain) rather than from simple considerations of spatial amplitude.

Further research is necessary considering other climatic variables such as precipitation and temperatures for different months and seasons (from annual to crop phenological periods). At the same time, an improvement in meteorological and crop damage data resolution with respect to time and/or space is necessary to explore a new type of analysis for finding significant relationships.

\section{Conclusions}

The results of other studies linking hail damage to minimum summer temperature in countries outside Spain did not agree with our results for Peninsular Spain. For some areas we found significant relationships; however, not all of them are relevant regarding hail incidence. We must recognise that the results of the analyses could be affected by the series length, by the data frequency (monthly or crop campaign), by the crop considered or by changes in the crop damage evaluation process. All these factors have an obvious influence on the study. On the other hand, we cannot dismiss the differences that might result from the specific dynamical characteristics of each area and from the special characteristics of each area's landscape and topography.

Acknowledgements. This work was supported by ENESA under projects P080220C-1065 and P090220C-822. AEMet is thankfully acknowledged for providing necessary data for this study.

Edited by: A. Gobin

Reviewed by: M. A. Rodrigues Rodrigues and three other anonymous referees

\section{References}

Alexandrov, V. A. and Hoogenboom, G.: Climate variation and crop production in Georgia, USA during the twentieth century, Clim. Res., 17, 33-43, 2001.

Berthet, C., Dessens, J., and Sanchez, J. L.: Regional and yearly variations of hail frequency and intensity in France, Atmos. Res., 100, 391-400, 2011.

Botzen, W. J. W., Bouwer, L. M., and van den Bergh, J. C. J. M.: Climate change and hailstorm damage: Empirical evidence and implications for agriculture and insurance, Resour. Energy Econom., 32, 341-362, 2010.

Camuffo, D. and Sturaro, G.: The climate of Rome and its action on monument decay, Clim. Res., 16, 145-155, 2001.

Changnon, D. and Bigley, R.: Fluctuations in US freezing rain days, Clim. Change, 69, 229-244, 2005.

Changnon, S. A. and Changnon, D.: Long-term fluctuations in hail incidences in the United States, J. Climate, 13, 658-664, 2000.

Changnon, S. A. and Changnon, D.: Long-term fluctuations in thunderstorm activity in the United States, Clim. Change, 50, 489503, 2001. 
Cohen, J. E. and Small, C.: Hypsographic demography: The distribution of human population by altitude, Proc. Natl. Acad. Sci. USA, 95, 14009-14014, 1998.

Dessens, J.: Severe convective weather in the context of a nighttime global warming, Geophys. Res. Lett., 22, 1241-1244, 1995.

Dimitrova, T., Mitzeva, R., and Savtchenko, A.: Environmental conditions responsible for the type of precipitation in summer convective storms over Bulgaria, Atmos. Res., 93, 30-38, 2009.

Fraile, R., Berthet, C., Dessens, J., and Sánchez, J. L.: Returns periods of severe hailfalls computed from hailpad data, Atmos. Res., 67-68, 189-202, 2003.

García-Ortega, E., Fita, L., Romero, R., López, L., Ramis, C., and Sánchez, J.L.: Numerical simulation and sensitivity study of a severe hailstorm in northeast Spain, Atmos. Res., 83, 225-241, 2007.

Hyvärinen, O. and Saltikoff, E.: Social Media as a Source of Meteorological Observations, Mon. Weather Rev., 138, 3175-3184, 2010.

Johns, R. H. and Doswell III, C. A.: Severe local storms forecasting, Weather Forecast, 7, 588-612, 1992.

Kunz, M.: The skill of convective parameters and indices to predict isolated and severe thunderstorms, Nat. Hazards Earth Syst. Sci., 7, 327-342, doi:10.5194/nhess-7-327-2007, 2007.

Liverman, D. M. and Merideth, R.: Climate and society in the U.S. Southwest: the context for a regional assessment, Clim. Res., 21, 199-218, 2002.

Llasat, M. C., Llasat-Botija, M., Barnolas, M., López, L., and Altava-Ortiz, V.: An analysis of the evolution of hydrometeorological extremes in newspapers: the case of Catalonia, 1982-2006, Nat. Hazards Earth Syst. Sci., 9, 1201-1212, doi:10.5194/nhess-9-1201-2009, 2009.

López, L., García-Ortega, E., and Sánchez, J. L.: A short term forecast model for hail, Atmos. Res., 83, 176-184, 2007.

Lynn, B. H., Druyan, L., Hogrefe, C., Dudhia, J., Rosenzweig, C, Goldberg, R., Rind, D., Healy, R., Rosenthal, J., and Kinney, P.: Sensitivity of present and future surface temperatures to precipitation characteristics, Clim. Res., 28, 53-65, 2004.

Manzato, A.: A climatology of instability indices derived from Friuli Venezia Giulia soundings, using three different methods, Atmos. Res., 67, 417-454, 2003.

McMaster, H. J.: The potential impact of global warming on hail losses to winter cereal crops in New South Wales, Clim. Change, 43, 455-476, 1999.
Mills, E.: Insurance in a Climate of Change, Science, 5737, 10401044, 2005.

Mills, E., Lecomte, E., and Peara, A.: Insurers in the greenhouse, J. Insurance Reg., 21, 43-78, 2002.

Piani, F., Crisci, A., De Chiara, G., Maracchi, G., and Meneguzzo, F.: Recent trends and climatic perspectives of hailstorms frequency and intensity in Tuscany and Central Italy, Nat. Hazards Earth Syst. Sci., 5, 217-224, doi:10.5194/nhess-5-217-2005, 2005.

Reddy, K. R., Doma, P. R., Mearns, L. O., Boone, M. Y. L., Hodges, H. F., Richardson, A. G., and Kakani, V. G.: Simulating the impacts of climate change on cotton production in the Mississippi Delta, Clim. Res., 22, 271-281, 2002.

Sánchez, J. L., Marcos, J. L., Dessens, J., López, L., Bustos, C., and García-Ortega, E.: Assessing sounding-derived parameters as storm predictors in different latitudes, Atmos. Res., 93, 446456, 2009.

Siedlecki, M.: Selected instability indices in Europe, Theoreti. Appl. Climatol., 96, 85-94, 2008.

Simeonov, P. and Giorgiev, C. G.: Severe wind/hail storms over Bulgaria in 1999-2001 period: synoptic- and meso-scale factors for generation, Atmos. Res., 67-68, 629-643, 2003.

Southworth, J., Pfeifer, R. A., Habeck, M., Randolph, J. C., Doering, O. C. and Rao, D. G.: Sensitivity of winter wheat yields in the Midwestern United States to future changes in climate, climate variability, and $\mathrm{CO}_{2}$ fertilization, Clim. Res., 22, 73-86, 2002.

Tao, F., Yokozawa, M., Zao, Z., Hayashi, Y., Grassl, H., and Fu, C.: Variability in climatology and agricultural production in China in association with the East Assian summer monsoon and El Niño Southern Oscillation, Clim. Res., 28, 23-30, 2004.

Tuovinen, J.-P., Punkka, A.-J., Rauhala, J., Hohti, H., and Schultz, D. M.: Climatology of Severe Hail in Finland: 1930-2006, Mon. Weather Rev., 137, 2238-2249, 2009.

Webb, J. D. C., Elsom, D. M. and Meaden, G. T.: Severe hailstorms in Britain and Ireland, a climatological survey and hazard assessment, Atmos. Res., 93, 587-606, 2009.

Willemse, S.: A statistical Analysis and climatological interpretation of hailstorms in Switserland, Doctor of Natural Sciences Thesis Dissertation No. 11137, Swiss Federal Institute of Technology, Zurich, 1995. 